\title{
Взаимосвязь агентских издержек и структуры собственности на примере российских и восточноевропейских компаний
}

\author{
Пирогов Н.К. ${ }^{9}$, Бобрышев Н.А. ${ }^{10}$
}

Статья представляет результаты эмпирического исследования агентских издержек на российском и восточноевропейском рынках. B качестве измерителей агентских издержек внутри компании выступают прокси-переменные, которые позволяют измерить влияние структуры собственности, состава совета директоров и банковского мониторинга. Результаты, полученные на выборке, состоящей из 131 компании, позволяют сделать выводы о том, что определенные аспекты агентской теории справедливы для российских компаний. Агентские издержки снижаются, если менеджеры компании увеличивают свою долю в ее акиионерном капитале; изменения в составе совета директоров способны оказывать влияние на агентские издержки; издержки возрастают, если в компании присутствует государственная собственность.

JEL: G30; $G 32$

Ключевые слова: агентские издержки, развивающиеся рынки, корпоративное управление, структура собственности

\section{Введение}

В соответствии с исследованиями Шляйфера и Вишни [Shleifer, Vishny, 1997], величина агентских издержек в начале 1990-х годов России достигала 99\% от стоимости компании. Ведущие отечественные специалисты в области корпоративного управления, такие как Т.Г.Долгопятова, В.В. Ковалев, А.В. Либман, А.Д. Радыгин, М. Старовойтов, Р.М. Энтов, А.А. Яковлев и другие, в своих исследованиях занимаются построением отечественной модели корпоративного управления, но уделяют недостаточно внимания причинам возникновения и методам контроля агентских издержек.

Основным инструментом анализа агентских издержек в России является ситуационный подход, который характеризуется достаточно большими вычислительными погрешностями. Использование современных эконометрических моделей может способствовать получению более точных оценок и выявлению скрытых закономерностей.

Дополнительные негативные факторы, способствующие возникновению агентских издержек, по мнению рейтинговых агентств «ЭкспертРА» и STANDARD\&POOR'S, - это недостаточная развитость рынка ценных бумаг и банковского сектора, незавершенность перехода к отчетности с использованием международных стандартов, непрозрачность, а иногда и закрытость структуры собственности у публичных компаний, а также несовершенство российского законодательства. Совокупность всех указанных факторов приводит к необходимости подробного исследования агентских издержек для повышения уровня корпоративного контроля в России.

\section{Обзор исследований на примере зарубежных компаний}

Исследованием корпоративных отношений в плоскости агентских издержек в экономической науке занимается теория агентских отношений. Примером подобных

\footnotetext{
${ }^{9}$ Старший преподаватель кафедры экономики и финансов фирмы ГУ ВШЭ.

${ }^{10}$ Стажер-исследователь Лаборатории корпоративных финансов ГУ ВШЭ.
}

Выпуск \#2(10), 2009

() Электронный журнал Корпоративные Финансы, 2009 
отношений служат отношения менеджера и акционера, менеджера и кредитора. В представленном исследовании изучаются агентские издержки, связанные с разделением в рамках компании функций собственника и управленца.

Начиная с момента возникновения агентской теории и до сегодняшнего дня большое число исследований, посвященных проблематике агентских издержек, было проведено на примере компаний развитых рынков. В своей статье, посвященной природе агентских издержек, Йенсен и Меклинг [Jensen, Meckling, 1976] сделали попытку оценить степень влияния внешних акционеров и заемного финансирования на возникновение агентских издержек в компании с использованием математического моделирования. Также одной из ранних работ, посвященных тематике агентских издержек, можно считать исследование, проведенное Фама [Fama, 1980], который описал компанию через математическую модель контрактных отношений.

В ранних исследованиях, проведенных в 1990-х годах, занимались поиском не агентских издержек как таковых, а изучали взаимосвязи между факторами, способными оказывать влияние на агентские издержки, получая через подобные соотношения выводы об изменениях агентских издержек и факторов, на них влияющих. К исследованиям подобного рода можно отнести работу Енсена, Солберга и Зорна [Jensen, Solberg, Zorn, 1992], которые в своей работе получили отрицательную зависимость между размером пакета акций, находящегося в собственности сотрудников компании, и уровнем выплаты дивидендов и положительную зависимость в случае заемного финансирования.

Схожие результаты были получены в исследовании Мохда, Перри и Римби [Moh'd, Perry, Rimbey, 1995] которые подтвердили, что величина акционерного пакета в руках менеджеров и уровень заемного финансирования (leverage) оказывают негативное влияние на уровень дивидендных выплат. Агравал и Кнобер [Agrawal, Knoeber, 1996] включили в рассмотрение такие механизмы, как доля акционерного капитала у инсайдеров, институциональных инвесторов и владельцев контрольных пакетов, число независимых директоров и кредитная политика компании. Похожие выводы, но для доли институциональной собственности, были получены исследователями Кручли, Енсен и др. [Crutchley, Jensen, Jahera, Raymond, 1999].

Другой подход, который используется авторами при проведении эмпирических исследований, основывается на увязывании факторов, контролирующих изменение агентских издержек и показателей деятельности фирмы. Взаимосвязь между элементами корпоративного управления, такими как размер совета директоров и состав его членов, и агентскими издержками часто исследуются авторами, интересующимися агентской проблематикой, в частности исследования размера совета директоров были проведены Ермаком [Yermack, 1996], Ейзинбергом, Сундгреном и Велсом [Eisenberg, Sundgren, Wells, 1998].

Исследованием состава совета директоров занимались такие экономисты, как Виер, Лианг и Макнайт [Weir, Laing, McKnight, 2002], Мак и Ли [Mak, Li, 2001], Бхагат и Блек [Bhagat, Black, 2002]. Виер, Лианг и Макнайт получили результаты, противоречащие агентской теории, то есть увеличение числа независимых директоров отрицательно влияет на показатель Q Тобина компании, а общее число членов совета - положительно. Мак и Ли в своем исследовании получили смешанные результаты.

Существует большое количество исследований, посвященных дуализму СЕО, составу и независимости наблюдательного совета, структуре компенсаций и денежных вознаграждений менеджменту: Брики, Коулз и Джаррел [Brickley, Coles, Jarrell, 1997], Ермак [Yermack, 1995].

Большая часть исследователей акцентируют внимание на изучении взаимосвязей, которые характеризуют отношения между долей владения акциями компании различными субъектами и показателями деятельности фирмы. Исследования Морка, Шляйфера и Вишни [Morck, Shleifer, Vishny, 1988] а также Макконела и Серваеса [McConnell, Servaes, 1990] 
показали, что существует нелинейная зависимость между изучаемыми переменными, которая является статистически значимой.

Исследования институциональной собственности не позволяют сделать однозначных выводов. Различные исследователи получают противоположные результаты при построении модели с участием подобного фактора. Макконел и Серваес в своем исследовании получили статистическую зависимость между показателями корпоративного управления и показателями деятельности фирмы. В противовес полученным результатам, Мак и Ли и Демзетс и Виллалонга [Demsetz, Villalonga, 2001] в своих работах на базе сингапурских (Мак и Ли) и американских (Демзетс и Виллалонга) компаний не получили статистической зависимости между институциональной собственностью и показателями компании.

Отдельный блок исследований посвящен рассмотрению не отдельных факторов в частности, а качеству общей системы менеджмента компании, что достигается за счет использования в моделировании таких переменных, как права акционеров или уязвимость к поглощению. Исследования, проведенные в этом направлении, были сделаны Блеком, Янгом и Кимом [Black, Jang, Kim, 2006] и Кремерсом и Наиром [Cremers, Nair, 2005].

Последний блок исследований связан с методикой, используемой в представленной работе. Авторы этих исследований делают попытку напрямую измерить уровень агентских издержек компании (или построить прокси-переменные) и также выделить факторы, которые оказывают значительное влияние на их изменение. Одной из первых работ в этом направлении была работа Анга, Коула и Лина [Ang, Cole, Lin, 2000] в которой авторы проводили измерение агентских издержек на примере небольших непубличных американских компаний.

Авторы использовали линейную многофакторную регрессию, в которую входили контрольные переменные плюс поочередно включались исследуемые наблюдения. Были выдвинуты гипотезы, что такие факторы, как доля собственности в руках менеджмента, наличие крупного акционера в компании и увеличение числа независимых директоров в составе совета, должны снижать агентские издержки компании. В итоге были получены результаты, полностью согласовывающиеся с агентской теорией.

Подобное исследование было проведено Флемингом, Хеани и Маккоскером [Fleming, Heany, McCosker, 2005] для непубличных австралийских компаний. Авторами была использована аналогичная методология и слегка расширенный набор переменных. Полученные результаты совпадают с выводами предыдущей модели. Работа Синга и Девидсона [Singh, Davidson, 2003] проводит аналогичные исследования, но на примере крупных американских компаний.

Таблица 1

Основные направления исследования агентских издержек

\begin{tabular}{|c|c|c|c|c|}
\hline Авторы & $\begin{array}{c}\text { Независимые } \\
\text { переменные }\end{array}$ & $\begin{array}{c}\text { Зависимая } \\
\text { переменная }\end{array}$ & Выборка & Результаты \\
\hline \multicolumn{5}{|c|}{ Математическое моделирование } \\
\hline $\begin{array}{c}\text { Jensen and } \\
\text { Meckling, } 1976\end{array}$ & \multirow{2}{*}{\multicolumn{3}{|c|}{$\begin{array}{c}\text { Математическое моделирование } \\
\text { математическое описание компании как набора } \\
\text { контрактных отношений }\end{array}$}} & $\begin{array}{c}\uparrow \text { акционерного } \\
\text { капитала } \\
\text { менеджмента } \downarrow \\
\text { А.И.* }\end{array}$ \\
\hline Fama, 1980 & & & & $\begin{array}{c}\uparrow \text { акционерного } \\
\text { капитала } \\
\text { менеджмента } \downarrow \text { А.И. }\end{array}$ \\
\hline \multicolumn{5}{|c|}{ Взаимосвязь переменных, определяющих агентские издержки, между собой } \\
\hline Jensen, Solberg & Дивиденды, & Дивиденды, & 1197 компаний & $\uparrow$ акционерного \\
\hline
\end{tabular}




\begin{tabular}{|c|c|c|c|c|}
\hline & \multirow{3}{*}{$\begin{array}{c}\text { уровень } \\
\text { финансового } \\
\text { рычага, структура } \\
\text { собственности, } \\
\text { контрольные } \\
\text { переменные }\end{array}$} & \multirow{3}{*}{$\begin{array}{c}\text { уровень } \\
\text { финансового } \\
\text { рычага, } \\
\text { структура } \\
\text { собственности }\end{array}$} & & $\begin{array}{c}\text { менеджмента и } \\
\text { уровня фин. рычага } \\
\downarrow \text { дивид. выплаты }\end{array}$ \\
\hline $\begin{array}{l}\text { Moh'd, Perry } \\
\text { and Rimbey, } \\
1995\end{array}$ & & & $\begin{array}{c}341 \text { компания } \\
\text { США }\end{array}$ & $\begin{array}{c}\uparrow \text { акционерного } \\
\text { капитала } \\
\text { менеджмента и } \\
\text { уровня фин. рычага } \\
\downarrow \text { дивид. выплаты }\end{array}$ \\
\hline $\begin{array}{c}\text { Crutchley, } \\
\text { Jensen, Jahera. } \\
\text { Raymond,1999 }\end{array}$ & & & $\begin{array}{c}815 \text { компаний } \\
\text { США }\end{array}$ & $\begin{array}{c}\uparrow \text { институц. } \\
\text { собственности } \downarrow \\
\text { дивид. выплаты и } \\
\text { уровень фин. рычага }\end{array}$ \\
\hline
\end{tabular}

Взаимосвязь переменных, определяющих агентские издержки, и эффективности деятельности компании

\begin{tabular}{|c|c|c|c|c|}
\hline $\begin{array}{c}\text { Agrawal and } \\
\text { Knoeber, } 1996\end{array}$ & $\begin{array}{c}\text { Структура } \\
\text { собственности, } \\
\text { совет директоров, } \\
\text { СЕО }\end{array}$ & Q Тобина & $\begin{array}{c}400 \text { крупных } \\
\text { компаний } \\
\text { США }\end{array}$ & $\begin{array}{c}\uparrow \text { акционерного } \\
\text { пакета менеджмента } \\
\uparrow \mathrm{Q} \text { Тобина, } \uparrow \text { уровня } \\
\text { фин. рычага и } \\
\text { независимости } \\
\text { совета } \downarrow \text { Q Тобина }\end{array}$ \\
\hline $\begin{array}{l}\text { Yermack, D., } \\
1996\end{array}$ & $\begin{array}{c}\text { Структура } \\
\text { собственности, } \\
\text { совет директоров, } \\
\text { СЕО }\end{array}$ & Q Тобина, ROA & $\begin{array}{c}452 \text { крупные } \\
\text { компании } \\
\text { США }\end{array}$ & \begin{tabular}{|c|}
$\uparrow$ размера совета \\
дир-ов $\downarrow$ ROA и Q- \\
Тобина, $\uparrow$ \\
акционерного пакета \\
менеджмента $\uparrow \mathrm{Q}$ \\
Тобина \\
\end{tabular} \\
\hline $\begin{array}{c}\text { Eisenberg, } \\
\text { Sundgren and } \\
\text { Wells, } 1998\end{array}$ & Совет директоров & $\mathrm{ROA}$ & $\begin{array}{c}879 \text { мелких } \\
\text { финских } \\
\text { компаний }\end{array}$ & $\begin{array}{c}\uparrow \text { размера совета } \\
\text { дир-ов } \downarrow \text { ROA }\end{array}$ \\
\hline $\begin{array}{c}\text { Weir, C., D. } \\
\text { Laing and P.J. } \\
\text { McKnight, } 2002\end{array}$ & $\begin{array}{c}\text { Структура } \\
\text { собственности, } \\
\text { совет директоров }\end{array}$ & Q Тобина & $\begin{array}{c}318 \text { крупных } \\
\text { английских } \\
\text { компаний }\end{array}$ & $\begin{array}{c}\uparrow \text { уровня фин. } \\
\text { рычага } \downarrow \text { Q-Тобина, } \\
\text { размер совета дир- } \\
\text { ов и число } \\
\text { независимых членов } \\
\uparrow \text { Q Тобина } \\
\end{array}$ \\
\hline $\begin{array}{l}\text { Mak, Y.T. and } \\
\text { Y. Li, } 2001\end{array}$ & $\begin{array}{c}\text { Структура } \\
\text { собственности, } \\
\text { совет директоров, } \\
\text { СЕО }\end{array}$ & Q Тобина & $\begin{array}{c}147 \\
\text { сингапурских } \\
\text { компаний }\end{array}$ & $\begin{array}{c}\uparrow \text { акционерного } \\
\text { пакета менеджмента } \\
\text { и размера совета } \\
\text { дир-ов } \downarrow \text { Q Тобина, } \uparrow \\
\text { независимости } \\
\text { совета } \uparrow \text { Q Тобина } \\
\end{array}$ \\
\hline $\begin{array}{c}\text { Morck, Shleifer } \\
\text { and Vishny, } \\
1988\end{array}$ & $\begin{array}{c}\text { Совет директоров } \\
\text { (нелинейно) }\end{array}$ & Q-Тобина & $\begin{array}{c}371 \text { крупная } \\
\text { компания } \\
\text { США }\end{array}$ & $\begin{array}{c}\text { Акционерный } \\
\text { капитал совета дир- } \\
\text { ов: 0-5\% и больше } \\
25 \% \text { - Q-Тобина } \uparrow, 5- \\
25 \% \text { Q-Тобина } \downarrow\end{array}$ \\
\hline
\end{tabular}

Построение единого показателя корпоративного управления, включающего в себя все прочие характеристики

\begin{tabular}{|c|c|c|c|c|}
\hline $\begin{array}{c}\text { Black, Jang and } \\
\text { Kim, 2006 }\end{array}$ & $\begin{array}{c}\text { Общий индекс } \\
\text { управления }\end{array}$ & Q Тобина & $\begin{array}{c}\text { 515 корейских } \\
\text { компании }\end{array}$ & $\begin{array}{c}\text { Улучение } \\
\text { корпоративного } \\
\text { управления снижает }\end{array}$ \\
\hline
\end{tabular}




\begin{tabular}{|c|c|c|c|c|}
\hline & & & & А.И. \\
\hline \multicolumn{5}{|c|}{ Измерение агентских издержек через прокси-переменные } \\
\hline $\begin{array}{l}\text { Fleming, Heany } \\
\text { and McCosker, } \\
2005\end{array}$ & \multirow{3}{*}{$\begin{array}{c}\text { Структура } \\
\text { собственности, } \\
\text { совет директоров, } \\
\text { контрольные }\end{array}$} & \multirow{3}{*}{$\begin{array}{c}\text { Прокси- } \\
\text { переменные, } \\
\text { измеряющие } \\
\text { агентские } \\
\text { издержки }\end{array}$} & $\begin{array}{c}3800 \\
\text { австралийских } \\
\text { компаний }\end{array}$ & $\begin{array}{c}\uparrow \text { акционерного } \\
\text { пакета менеджмента } \\
\text { и семейной } \\
\text { собственности } \downarrow \\
\text { А.И. }\end{array}$ \\
\hline $\begin{array}{l}\text { Ang, Cole and } \\
\text { Lin, } 2000\end{array}$ & & & $\begin{array}{c}1708 \\
\text { небольших } \\
\text { компаний } \\
\text { США }\end{array}$ & $\begin{array}{c}\uparrow \text { акционерного } \\
\text { пакета менеджмента } \\
\text { и уровня фин. } \\
\text { рычага } \downarrow \text { А.И., } \\
\text { большое число } \\
\text { акционеров } \uparrow \text { А.И. }\end{array}$ \\
\hline $\begin{array}{c}\text { Singh and } \\
\text { Davidson, } 2003\end{array}$ & & & $\begin{array}{l}1528 \text { крупных } \\
\text { компаний } \\
\text { США }\end{array}$ & $\begin{array}{c}\uparrow \text { акционерного } \\
\text { пакета менеджмента } \\
\downarrow \text { А.И., } \uparrow \text { размера } \\
\text { совета дир-ов } \uparrow \text { А.И. }\end{array}$ \\
\hline
\end{tabular}

*А.И. - агентские издержки.

Из рассмотренных работ большая часть посвящена исследованию развитых рынков. Несмотря на это, в последнее время многие зарубежные авторы стали обращать внимание на развивающиеся страны, преимущественно азиатского региона.

В эмпирических работах по российским данным, проведенных сотрудниками ГУ ВШЭ Т.Г. Долгопятовой и А.А. Яковлевым, были выявлены факторы, способствующие возникновению агентских издержек: особенности российской приватизации [Яковлев, 2003], переход акционерного капитала к другим нефинансовым компаниям [Долгопятова, 2004], присутствие во многих компаниях. крупного собственника, тенденции по найму топменеджеров, не являющихся собственниками акционерного капитала компании [Долгопятова, 2007].

В основном отечественные исследования направлены на общую оценку корпоративного управления компании. Несмотря на это, по аналогии с зарубежными работами можно сделать косвенные выводы о факторах, оказывающих влияние на агентские издержки.

\section{Описание переменных и гипотез}

В модели исследования используются четыре зависимые переменные: коэффициент использования активов (asset utilization ratio), уровень операционных издержек (expense ratio), величина свободных денежных потоков компании (free cash flows) и проксипеременная агентских издержек, основывающаяся на показателе Q Тобина (Q Tobin's ratio).

Первая зависимая переменная - коэффициент использования активов (AssetUtilization) - определяется как отношение выручки к общей величине активов (annual sales to total assets) и отрицательно коррелирован с агентскими издержками. Высокие значения показателя означают, что менеджмент принимает эффективные инвестиционные решения и извлекает максимальную производительность из имеющихся активов и, как следствие, менее склонен к генерации агентских издержек в рамках компании.

Вторая зависимая переменная - уровень операционных издержек (ExpenceRatio) определяется отношением операционных издержек к выручке. В проведенном исследовании величина операционных издержек определялась как сумма коммерческих расходов и расходов на маркетинг, общих и административных расходов (selling general and 
administrating expenses), амортизация и прочие операционные расходы. Показатель операционных издержек положительно связан с уровнем агентских издержек компании и является прямым измерителем агентских издержек, так как нецелевые расходы топменеджмента на частные выгоды будут отражены в общих и административных расходах. Две первые переменные были предложены в качестве зависимых в исследовании, проведенном авторами Ангом, Коулом и Лином [Ang, Cole, Lin, 2000]

Третья зависимая переменная, способная выявить уровень агентских издержек, - это соотношение потоков свободных денежных средств к общей величине активов (FCF/TA). Наличие свободных денежных средств в компании является фактором, который заставляет менеджеров принимать неэффективные инвестиционные решения или использовать денежные средства не по назначению, так как свободные денежные потоки по своей сути это избыток средств, который остается после того, как все выгодные инвестиционные решения уже реализованы [Jensen, 1986].

Последняя переменная (Qdummy) является бинарной и основывается на показателе Q Тобина. Она принимает значение 1 в случае, если Q Тобина компании больше единицы, и 0 - если Q-Тобина меньше единицы. В исследовании значение Q Тобина рассчитывалось как отношение рыночной капитализации к совокупным активам (market capitalization to total assets). Описанная переменная позволяет опосредованно предполагать наличие агентских издержек у компаний, значение Q Тобина в которых меньше единицы, так как менеджеры фирмы уменьшают стоимость акционерного капитала (shareholder's value) и, предполагается, с большей вероятностью склонны к пользованию частными выгодами за счет компании, что создает агентские издержки для акционеров компании. Переменные FCF/TA и Qdummy были построены по аналогии с работой Генри [Henry, 2006], где они и представлены.

Независимые переменные можно разделить на три группы: переменные корпоративного управления; переменные, характеризующие деятельность совета директоров; и контрольные переменные. 
Характеристики переменных

\begin{tabular}{|c|c|c|}
\hline \multicolumn{3}{|c|}{ Зависимые переменные } \\
\hline ExpenceRatio & $\begin{array}{c}\text { Operating Exp/ Annual } \\
\text { Sales }\end{array}$ & Уровень операционных расходов \\
\hline AssetUtitilization & $\begin{array}{c}\text { Annual Sales/ Total } \\
\text { Assets }\end{array}$ & Коэффициент использования активов \\
\hline $\mathrm{FCF} / \mathrm{TA}$ & FCF/Total Assets & $\begin{array}{c}\text { Отношение свободных денежных потоков } \\
\text { к величине активов }\end{array}$ \\
\hline Qdummy & Бинарная & Qдамми \\
\hline \multicolumn{3}{|c|}{ Переменные структуры собственности } \\
\hline Man_Own & Бинарная & Менеджер-владелец \\
\hline ManrShare & Доля & Пакет акций во владении менеджмента \\
\hline ManrShare $^{\wedge} 2$ & Доля^2 & Квадрат переменной ManrShare \\
\hline FstShrOwn & Доля & Пакет акций основного акционера \\
\hline Own $>50$ & Бинарная & Если доля \\
\hline NonManSharehls & $\begin{array}{c}\text { Натуральный } \\
\text { логарифм }\end{array}$ & Число неуправляющих акционеров \\
\hline GovOwn & Доля & Доля государства в компании \\
\hline \multicolumn{3}{|c|}{ Переменные совета директоров } \\
\hline BoDSize & Число & Количество участников совета директоров \\
\hline BoDInd & Доля & $\begin{array}{c}\text { Отношение числа независимых } \\
\text { директоров к общей численности совета }\end{array}$ \\
\hline \multicolumn{3}{|c|}{ Контрольные переменные } \\
\hline Leverage & Total debt/Total Assets & Уровень банковского контроля \\
\hline Ind & Бинарная & Код отрасли \\
\hline Size & $\begin{array}{c}\text { Натуральный } \\
\text { логарифм }\end{array}$ & Размер компании \\
\hline Age & Год & Возраст \\
\hline
\end{tabular}

Основываясь на агентской теории, предложенной Енсеном и Мекленгом [Jensen, Meckling, 1976), и используя опыт предыдущих исследований, можно обозначить гипотезы относительно влияния различных факторов на агентские издержки.

Гипотеза 1. Увеличение пакета акций в руках менеджмента приводит к выравниванию интересов менеджмента и собственников и снижает агентские издержки. Это означает, что коэффициенты $\beta_{1}, \beta_{2}$ перед переменными Man_Own и ManrShare должны быть значимыми и отрицательными.

Гипотеза 2. Сосредоточение крупного пакета акций в руках одного собственника стимулирует усиление мониторинга с его стороны, снижая агентские издержки. Коэффициенты $\beta_{4}, \beta_{5}$ должны быть значимыми и отрицательными.

Гипотеза 3. Размытие структуры собственности приводит к возникновению дополнительных агентских издержек. Переменная NonManSharehls должна входить в уравнения с положительным коэффициентом $\beta_{6}$.

Гипотеза 4. Состав и размер совета директоров способны оказать значительное влияние на агентские издержки в контексте российских и восточноевропейских компаний. Коэффициенты $\beta_{8}, \beta_{9}$ должны быть значимыми. 
Гипотеза 5. Государственная собственность способствует снижению эффективности функционирования компании и приводит к возникновению дополнительных агентских издержек, то есть переменная GovOwn должна входить в уравнения с положительным коэффициентом $\beta_{7}$.

Исследование зависимостей производилось с помощью линейных регрессий, в которых в качестве зависимой переменной выступала одна из четырех переменных, характеризующих уровень агентских издержек компании, а объясняющими переменными выступали поочередно переменные структуры собственности и структуры совета директоров. Оценка параметров регрессии производилась обычным МНК-методом. При построении регрессии для бинарной переменной общая форма регрессионной зависимости представлена следующим образом:

(1)

Agency costs $_{i}=\alpha+\beta_{1}\left(\right.$ Man_Owner $\left._{i}\right)+\beta_{2}\left(\right.$ ManrShare $\left._{i}\right)+$

$\beta_{3}\left(\right.$ ManShare $\left.^{\wedge} 2_{i}\right)+\beta_{4}\left(\right.$ FstShrOwn $\left._{i}\right)+\beta_{5}\left(O w n>50_{i}\right)+$

$\beta_{6}\left(\right.$ NonManSharehls $\left._{i}\right)+\beta_{7}\left(\right.$ GovOwn $\left._{i}\right)+\beta_{8}\left(\right.$ BoDSize $\left._{i}\right)+$

$\beta_{9}\left(\right.$ BoDInd $\left._{i}\right)+\beta_{10}\left(\right.$ Leverage $\left._{i}\right)+\beta_{11}\left(\right.$ Size $\left._{i}\right)+\beta_{12-18}\left(\right.$ Ind $\left._{i}\right)+$

$\beta_{11}\left(A g e_{i}\right)+\varepsilon_{i}$

где:

агентские издержки (agency costs) - одна из четырех независимых переменных;

$\alpha$ - константа регрессии;

$\beta_{j}$ - коэффициенты независимых переменных;

$\varepsilon_{i}$ - компонента ошибок регрессии.

Чтобы отсечь влияние других факторов на зависимую переменную, так как возможная корреляция между независимыми переменными приведет к ухудшению оценок регрессии, использовалась более простая форма эконометрической зависимости:

Agency $\operatorname{Costs}_{i}=\alpha_{i}+\beta_{1}($ InependentVariable $)+\beta_{2}($ Leverage $)+\beta_{3}($ Size $)+$

$\beta_{4-10}($ Ind $)+\beta_{11}($ Age $)+\varepsilon_{i}$

где:

независимая переменная (Independent Variable) - одна из переменных структуры собственности или банковского контроля.

Полная форма регрессии строилась для проверки полученных результатов. Среди зависимых переменных присутствует одна бинарная (Qdummy), поэтому оценки регрессионных уравнений с участием этой переменной проводились с использованием logit модели.

\section{Характеристики выборки}

Данное исследование проведено на основе выборки, объединяющей результаты деятельности российских и восточноевропейских компаний. Использование межстрановой выборки связано с нехваткой информации в рамках российской экономики. Такие страны Восточной Европы, как Чехия, Венгрия, Румыния, Польша, государства Балтийского региона, были выбраны из-за схожести развития рыночных отношений, становление которых началось после распада Советского Союза и одновременно ухода от коммунистического режима, в соседних «дружественных» странах. К странам Балтийского региона относятся Латвия, Литва и Эстония. 
Данные собирались с использованием таких международных баз данных, как «Амадеус» от компании «ВанДайк» (Amadeus by bureau Van Dijk) и «Блумберг» (Bloomberg).

Выборка содержит информацию о 131 компании по состоянию на конец 2007 года, распределение компаний по странам можно увидеть в таблице 3. В связи с тем, что раскрытие финансовой информации в России и странах Восточной Европы находится на достаточно низком уровне, в рассмотренную выборку вошли в основном крупные компании.

Таблица 3

Распределение компаний всей выборки по странам на 2007 г. (шт.)

\begin{tabular}{|l|l|l|l|l|l|}
\hline Россия & Чехия & Венгрия & Румыния & Польша & Страны Балтии \\
\hline 58 & 6 & 12 & 20 & 20 & 15 \\
$(44,27 \%)$ & $(4,85 \%)$ & $(9,16 \%)$ & $(15,27 \%)$ & $(15,27 \%)$ & $(11,45 \%)$ \\
\hline
\end{tabular}

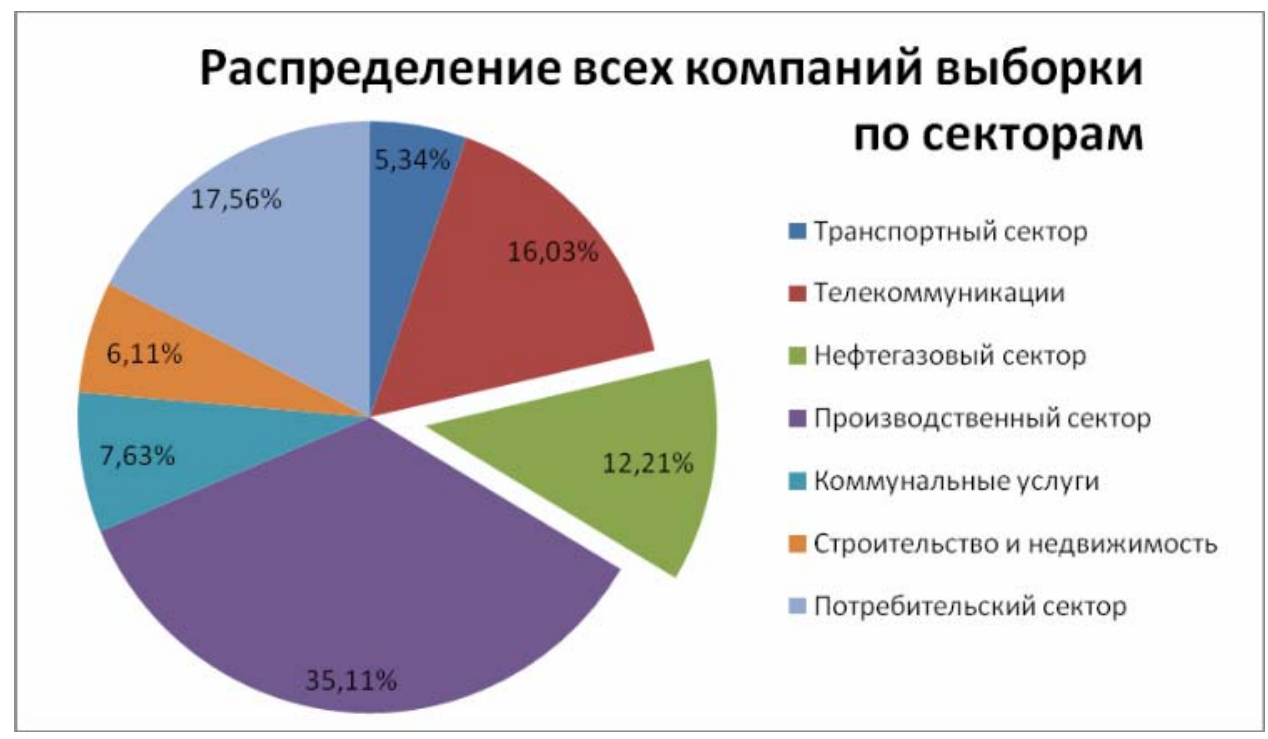

Рис. 1. Распределение всех компаний по секторам на 2007 г. (\%)

Так как число наблюдений невелико, то для уменьшения числа дамми-переменных была проведена агрегация по индустриям для компаний со схожими показателями. Как следует из рисунка 1, в выборке преобладают компании производственного сектора. При этом значительна доля компаний потребительского и телекоммуникационных секторов.

Среднее значение коэффициента использования активов по исследуемой выборке составило 0,75 , что несколько ниже, чем результаты, полученные для Австралии $(0,85)$ [Henry, 2006] и значительно отличается от США $(1,46)$ [Singh, Davidson, 2003]. Полученные результаты также соотносятся с работой Бхатачаруя и Pao [Bhattacharyya, Vivek Rao, 2005], которые исследовали агентские издержки на индийских компаниях $(0,84)$.

Результаты для среднего значения уровня операционных издержек выше, чем в США примерно в полтора раза (0,375 в сравнении с 0,29), но значительно ниже, чем в Индии, где показатель составил 1,03 .

В России и Европе (здесь и в дальнейшем подразумеваются страны Восточной Европы) примерно одинаковое число компаний, которые генерируют отрицательные и положительные потоки свободных денежных средств, так как среднее значение составляет 0,004 и оно незначительно отличается от медианы 0,006 .

Говоря о переменных структуры собственности, можно отметить, что почти в половине случаев $(46,66 \%)$ менеджеры компании владеют ее акциями в среднем в размере 
11,4\%, что схоже с результатами, полученными для Великобритании -12,09\% [Short, Keasey, 1999]. Этот показатель ниже среднего для США (16,19\%), но больше австралийских данных $(6 \%)$.

Показатель численности совета директоров во всех рассмотренных исследованиях примерно одинаков, и в среднем совет директоров состоит из восьми членов, но средней показатель независимости для российской и европейской выборки $(31,1 \%)$ значительно ниже, чем в Индии, - 87,5\% [Bhattacharyya, Vivek Rao, 2005] и США - 56,81\% [Singh, Davidson, 2003]. Можно предположить, что, скорее всего, число членов совета директоров будет положительно коррелировать с агентскими издержками.

Таблица 4

Характеристики общей выборки компаний

\begin{tabular}{|l|l|l|l|l|l|l|}
\hline & Переменная & Среднее & Дисперсия & Среднекв. откл. & Минимум & Максимум \\
\hline 1 & AssetUtitilization & 0,759 & 0,119 & 0,345 & 0,034 & 1,492 \\
\hline 2 & ExpenceRatio & 0,375 & 0,052 & 0,227 & 0,046 & 0,838 \\
\hline 3 & FCF/TA & $-0,004$ & 0,009 & 0,095 & $-0,326$ & 0,247 \\
\hline 4 & Qdummy & 0,618 & 0,236 & 0,486 & 0,000 & 1,000 \\
\hline 5 & Man_Owner & 0,466 & 0,249 & 0,499 & 0,000 & 1,000 \\
\hline 6 & ManrShare & 0,114 & 0,040 & 0,201 & 0,000 & 0,864 \\
\hline 7 & FstShrOwn & 0,503 & 0,040 & 0,200 & 0,094 & 0,936 \\
\hline 8 & Own>50 & 0,542 & 0,248 & 0,498 & 0,000 & 1,000 \\
\hline 9 & NonManSharehls & 19,3 & 978,0 & 31,3 & 0,0 & 300,0 \\
\hline 10 & GovOwn & 0,149 & 0,071 & 0,266 & 0,000 & 0,966 \\
\hline 11 & BoDSize & 7,802 & 6,800 & 2,608 & 3,000 & 15,000 \\
\hline 12 & BoDInd & 0,311 & 0,042 & 0,205 & 0,000 & 1,000 \\
\hline 13 & Leverage & 0,224 & 0,024 & 0,154 & 0,000 & 0,577 \\
\hline 14 & Size & 6,605 & 3,670 & 1,916 & 1,480 & 11,460 \\
\hline 15 & Age & 27,213 & 833,817 & 0,382 & 2,000 & 149,000 \\
\hline
\end{tabular}

Среди общего числа компаний российскими компаниями являются 58, восточноевропейскими - 73. В таблице 5 и на рисунках 2 и 3 приведены основные характеристики региональных подвыборок. Сходство обеих выборок заключается в превалировании компаний производственного сектора, а также в примерно одинаковом соотношении компаний транспортного сектора, коммунальных услуг и предприятий нефтегазового сектора. 


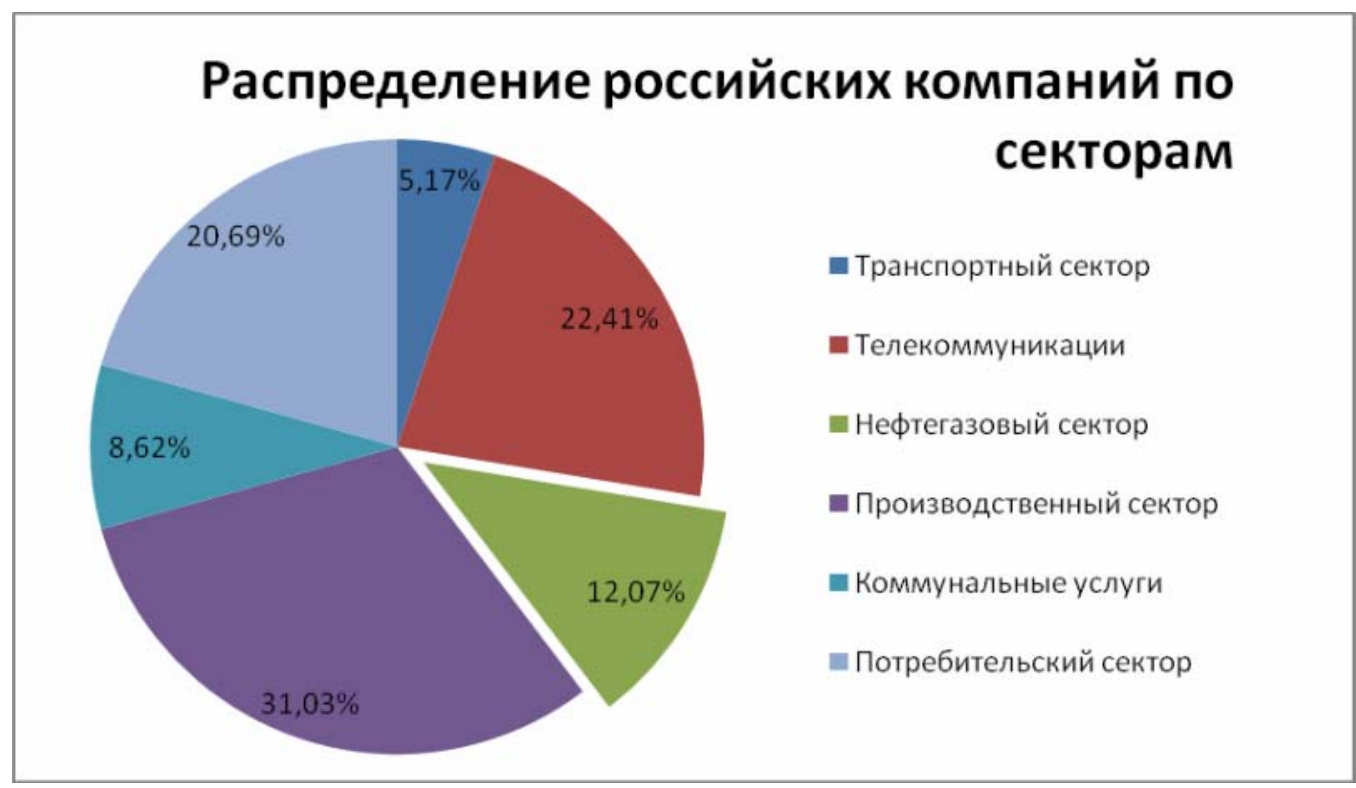

Рис. 2. Распределение всех компаний по секторам на 2007 г. (\%)

Как следует из рисунка 2, в рамках отобранных компаний, на российском рынке, в отличие от восточноевропейского, не представлены компании строительного сектора, при этом доля телекоммуникационных - в два раза выше. Компании телекоммуникационного сектора характеризуются относительно небольшими операционными затратами по сравнению с компаниями строительного сектора, поэтому отраслевые различия окажут влияние на средние значения описательных статистик. Рисунки 2 и 3 демонстрируют распределение компаний по секторам.

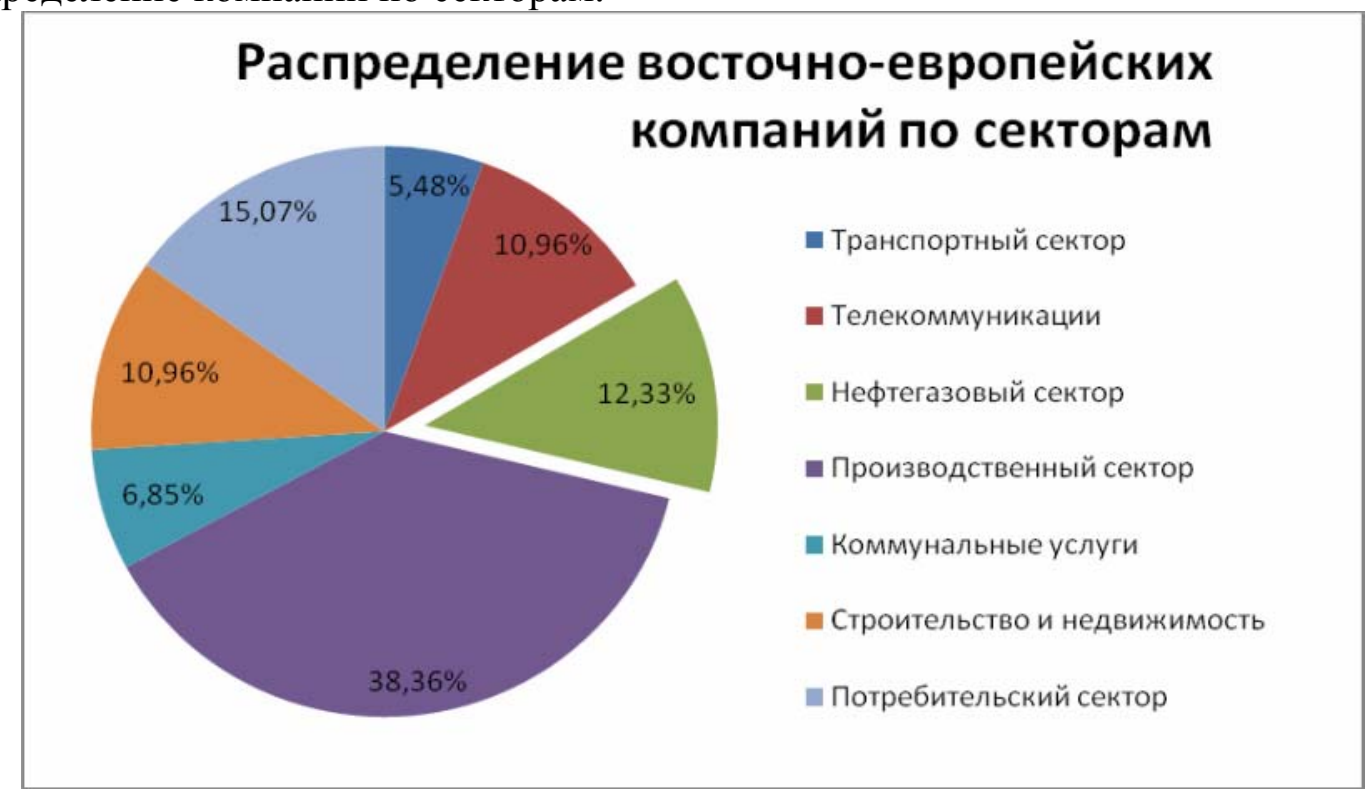

Рис. 3. Распределение восточно-европейских компаний по секторам на 2007 г. (\%)

Как следует из таблицы 5, описательные характеристики двух подвыборок в основном отличаются незначительно, но можно указать некоторые особенности. Средние значения переменной AssetUtitilization для российских и европейских компаний отличаются на 10,4\%. Средние значения переменной ManrShare различаются почти вдвое. Это может привести к тому, что для европейской подвыборки влияние акционерного капитала окажется менее 
значимым. Для европейских компаний менее характерно присутствие государства среди собственников; среднее значение этого показателя для российских компаний составляет 0,196 и оно больше европейского показателя в 1,75 раз. Аналогичная ситуация складывается относительно присутствия в компании крупного мажоритария. Для восточноевропейских компаний характерны большая независимость совета директоров (почти в два раза) и меньшее число общих членов в составе совета.

Таблица 5

Характеристики российской и восточноевропейской выборок

\begin{tabular}{|l|l|l|l|l|l|l|l|}
\hline & & \multicolumn{3}{|l|}{ Российские компании } & \multicolumn{3}{l|}{ Bосточно-европейские компании } \\
\hline & & Среднее & Максимум & Минимум & Среднее & Максимум & Минимум \\
\hline 1 & AssetUtitilization & 0,817 & 1,492 & 0,234 & 0,713 & 1,479 & 0,034 \\
\hline 2 & ExpenceRatio & 0,390 & 0,807 & 0,071 & 0,363 & 0,838 & 0,046 \\
\hline 3 & FCF/TA & 0,000 & 0,185 & $-0,326$ & $-0,007$ & 0,247 & $-0,295$ \\
\hline 4 & Qdummy & 0,690 & 1,000 & 0,000 & 0,562 & 1,000 & 0,000 \\
\hline 5 & Man_Owner & 0,586 & 1,000 & 0,000 & 0,370 & 1,000 & 0,000 \\
\hline 6 & ManrShare & 0,158 & 0,864 & 0,000 & 0,078 & 0,546 & 0,000 \\
\hline 7 & FstShrOwn & 0,553 & 0,936 & 0,094 & 0,463 & 0,868 & 0,100 \\
\hline 8 & Own>50 & 0,690 & 1,000 & 0,000 & 0,425 & 1,000 & 0,000 \\
\hline 9 & NonManSharehls & 21,0 & 300,0 & 0,0 & 18,0 & 91,0 & 0,0 \\
\hline 10 & GovOwn & 0,196 & 0,966 & 0,000 & 0,112 & 0,900 & 0,000 \\
\hline 11 & BoDSize & 9,241 & 15,000 & 5,000 & 6,658 & 13,000 & 3,000 \\
\hline 12 & BoDInd & 0,222 & 0,636 & 0,000 & 0,382 & 1,000 & 0,000 \\
\hline 13 & Leverage & 0,268 & 0,577 & 0,000 & 0,190 & 0,572 & 0,000 \\
\hline 14 & Size & 7,762 & 11,468 & 4,235 & 5,686 & 10,176 & 1,481 \\
\hline 15 & Age & 33,431 & 141,000 & 2,000 & 22,274 & 149,000 & 2,000 \\
\hline
\end{tabular}

Переменные AssetUtitilization и ExpenceRatio имеют сильную отрицательную корреляцию $(-0,3)$, что подтверждает разнонаправленное влияние переменных на величину агентских издержек. Отсутствует корреляция переменной Qdummy с другими переменными, характеризующими агентские издержки, так как мы предполагаем, что AssetUtitilization и Qdummy $(0,07)$ имеют однонаправленное влияние на агентские издержки, то их совместное использование позволит более полно учесть влияние различных факторов.

Переменная FstShrOwn имеет значимую положительную корреляцию только с Qdummy $(0,14)$, переменная Own $>50$ c AssetUtitilization $(0,11)$, при этом значение корреляции с остальными объясняемыми переменными положительно. Определение более точных взаимосвязей требует построения эконометрических моделей.

Переменная BoDSize коррелирует с FCF/TA $(0,22)$ и ExpenceRatio $(0,16)$, поэтому при построении модели можно предполагать наличие значимых коэффициентов с нужным знаком.

Корреляционная зависимость между GowOwn и переменными агентских издержек AssetUtitilization и Qdumm положительна, между переменными ExpenceRatio, FCF/TA отрицательна, что косвенно подтверждает выдвинутую гипотезу. 


\section{Результаты оценивания модели}

Проведя исследование зависимости агентских издержек от переменных, контролирующих структуру собственности компании, состав совета директоров, уровень банковского мониторинга на выборке, состоящей из российских и восточноевропейских компаний, можно выделить факторы, которые в наибольшей степени оказывают влияние.

В ходе проведенного исследования частично подтвердилась первая гипотеза о том, что наличие акций компании в собственности у менеджмента способствует снижению агентских издержек. В результате исследования зависимости между наличием в компании менеджерасобственника (Man_Owner) и изменением агентских издержек на примере российских и восточноевропейских компаний не было выявлено устойчивой взаимосвязи, которая позволяла бы делать определенные выводы.

В ходе исследования была подтверждена первая гипотеза. Выявлена устойчивая зависимость между агентскими издержками и величиной менеджерского пакета акций. Исследование показало, что увеличение пакета акций компании в руках менеджмента приводит к оптимальному распределению ресурсов в компании и снижению агентских издержек, что связано с выравниванием интересов акционеров и менеджеров в рамках одной компании. Результаты согласуются с исследованиями, проведенными в рамках американской экономики авторами Сингом и Девидсоном [Singh, Davidson, 2003] и Генри [Henry, 2006] на примере крупных австралийских компаний.

Вторая гипотеза, о положительном влиянии крупного акционера на уровень мониторинга, на представленной выборке не подтвердилась. Переменные, которые отслеживают наличие в компании крупного акционера и изменение числа его акций, в результате проведенных эконометрических исследований оказались незначимыми.

Сделанные выводы подтверждают состоятельность третьей гипотезы об отрицательном влиянии общего числа акционеров на агентские издержки компании. Размытие структуры собственности компании, которое выражается в большом числе акционеров, владеющих относительно небольшими пакетами акций, позволяет менеджменту копании более активно продвигать проекты, направленные на извлечение собственной выгоды. Наличие большого числа акционеров приводит к проблеме безбилетника, когда участники отношений стараются переложить свои обязанности на других, тем самым снижая общий уровень мониторинга за деятельностью менеджмента и стимулируя возникновение агентских издержек. Подобные выводы были получены в исследовании, проведенном авторами Ангом, Коулом и Лином [Ang, Cole, Lin, 2000].

Гипотеза номер четыре, предполагающая значимое влияние совета директоров на менеджмент компании, подтвердилась, причем по результатам исследования, возможно четко определить направленность влияния факторов, характеризующих деятельность совета директоров.

Присутствие в составе совета независимых членов позволяет осуществлять дополнительный мониторинг за деятельностью менеджеров, что повышает качество управления компанией. Степень независимости совета директоров статистически значима как для выборки в целом, так и для российских компаний в частности. Как было отмечено, уровень независимости совета в российских компаниях намного ниже, чем в зарубежных, поэтому необходимо увеличить число независимых директоров для повышения эффективности деятельности компании.

Полученные взаимосвязи между деятельностью совета директоров и корпоративным управлением согласуются с другими исследованиями, например с работой Синга и Девидсона [Singh, Davidson, 2003], Ермака [Yermack, 1996]. Влияние размера совета директоров на показатели компании оказалось отрицательным, то есть привлечение большого числа директоров приводит к возникновению дополнительных агентских издержек. 
Исследование показало состоятельность пятой гипотезы о том, что государственная собственность негативно влияет на показатели деятельности компании. На примере российских и восточноевропейских компаний нам удалось убедиться, что наличие государства среди акционеров компании приводит к возникновению дополнительных агентских издержек. Это утверждение справедливо как для всей выборки в целом, так и для российских и восточноевропейских компаний по отдельности. Результат аналогичен полученному в работе Сай, Хиллер и Тиан [Cai, Hillier, Tian, 2009], в которой подобные выводы были сделаны на примере китайских компаний; также наши выводы согласуются с экспертными оценками рейтинговых агентств, проводивших свои исследования в Российской Федерации.

В рамках проведенного исследования были обнаружены статистически значимые связи между объясняемыми переменными и таким фактором, как доля заемных средств. Банковский мониторинг заставляет менеджеров принимать более эффективные решения, что снижает стимулы к оппортунистическому поведению и, как следствие, агентские издержки, что было подтверждено на исследуемой выборке.

В ходе исследования не было обнаружено однозначной взаимосвязи между агентскими издержками и размером компании, несмотря на то что во многих моделях переменная являлась статистически значимой. Выборка состояла преимущественно из средних и крупных компаний, можно было предположить, что будет наблюдаться экономия издержек от масштаба, но однозначной закономерности получить не удалось.

\section{Проверка результатов на локальных выборках}

Устойчивость полученных результатов можно проверить с помощью разделения выборки на две подвыборки и построения аналогичных эконометрических моделей на части данных. Также интересно увидеть, какие закономерности сохранятся при исследовании непосредственно российских компаний. С этой целью исходный набор данных был разделен на две группы: Россия и Восточная Европа. «Российская» часть выборки представлена 58 компаниями, «Европейская» часть представлена 73 компаниями. Перед построением моделей необходимо указать некоторые допущения, которые связаны с небольшим размером исходной выборки.

Использование полного набора объясняемых переменных не представляется возможным, так как при определении оценок переменных не достигается минимизация квадратов ошибок. По этой причине в качестве контрольных переменных будут использованы только переменных Size и Leverage.

Для российских компаний выявленные значимые переменные не вошли в противоречие с ранее полученными результатами, а наоборот, позволили убедиться в правильности получаемых выводов. Знаки незначимых коэффициентов во много совпадают с описанными результатами.

Переменные ManrShare, GowOwn, NonManSharehls, BoDSize, BoDInd оказались значимыми, и полученные знаки соответствуют теоретическим предпосылкам.

Таблица 6

Влияние исследуемых переменных на агентские издержки на российской выборке

\begin{tabular}{|l|l|l|l|l|}
\hline Man_Owner & ManrShare & FstShrOwn & Own $>50$ & NonManShrs \\
\hline Heт & $(-)^{*}$ & Heт & $(+)$ & $(+)^{*}$ \\
\hline GovOwn & BoDSize & BoDInd & Leverage & Size \\
\hline$(+)^{*}$ & $(+)^{*}$ & $(-)^{*}$ & Нет & Нет \\
\hline
\end{tabular}

* Отмечены значимые переменные 
Результаты, полученные при оценке переменных на основании данных восточноевропейских компаний, не позволяют сделать какие-либо выводы о наличии зависимости между структурой собственности и агентскими издержками. Из всех переменных, характеризующих структуру собственности, значимыми оказались только показатели государственной собственности и числа неуправляющих акционеров, также была значима переменная общего числа совета директоров.

Таблица 7 Влияние исследуемых переменных на агентские издержки на восточноевропейской выборке

\begin{tabular}{|l|l|l|l|l|}
\hline Man_Owner & ManrShare & FstShrOwn & Own $>50$ & NonManShrs \\
\hline Нет & Нет & Нет & Нет & $(+)^{*}$ \\
\hline GovOwn & BoDSize & BoDInd & Leverage & Size \\
\hline$(+)^{*}$ & $(+)^{*}$ & Нет & Нет & Нет \\
\hline
\end{tabular}

* Отмечены значимые переменные

\section{Заключение}

Агентские издержки, которые возникают в результате разделения функций управления и контроля в компании, способны в значительной степени повлиять на эффективность корпоративного управления. Представленное исследование делает попытку проследить взаимосвязь между различными факторами деятельности компании, в частности такими, как структура собственности, банковский мониторинг и эффективность деятельности совета директоров, с целью определения степени их влияния на агентские издержки.

В качестве исследовательского инструмента выступали два регрессионных уравнения, разработанные по аналогии с работами других исследователей [Ang, Cole, Lin, 2000; Fleming, Heany, McCosker, 2005]. В рамках этих уравнений проводилось исследование взаимодействий между четырьмя прокси-переменными агентских издержек и набором независимых факторов, отписывающих корпоративную структуру компании, банковский мониторинг и прочие контрольные величины.

Исследование проводилось с использованием данных, характеризующих деятельность российских и восточноевропейских компаний. В ходе проведенного эконометрического анализа удалось выявить определенные закономерности.

1. Увеличение пакета акций, находящегося в руках менеджмента компании, приводит к выравниванию интересов и целей акционеров и управляющего состава, то есть снижению агентских издержек. Результаты согласуются с исследованиями, проведенными в рамках американской экономики авторами Сингом и Девидсоном [Singh, Davidson, 2003] и Генри [Henry, 2006] на примере крупных австралийских компаний.

2. Присутствие государства в составе акционеров компании не способствует появлению дополнительных факторов мониторинга, а приводит к увеличению агентских издержек, причем это справедливо для всех компаний. Результат аналогичен полученному в работе Сай, Хиллер и Тиан [Cai, Hillier, Tian, 2009].

3. Размытие структуры собственности приводит к возникновению проблемы безбилетника и, как следствие, снижению мониторинга и увеличению агентских издержек.

4. Роль совета директоров, как контролирующего органа и посредника между акционерами и менеджментом, чрезвычайно важна в деятельности компании. Состав и размер совета директоров способны оказывать существенное влияние на качество корпоративного управления в компании. Результаты совпадают с исследованиями Синга и Дэвидсона [Singh, Davidson, 2003], Ермака [Yermack, 1996]. 
Полученные результаты позволяют говорить о том, что для российских и восточноевропейских компаний контроль агентских издержек является не только теоретической моделью, но реальным фактором, способным привести к улучшению качества корпоративного контроля и поднять эффективность деятельности предприятия.

Дальнейшие исследования в этой области можно сосредоточить на расширении списка факторов структуры собственности. Для отражения более полной картины в исследование можно ввести институциональных инвесторов, а также рассмотреть нелинейные взаимодействия между величиной акционерного капитала и изменением агентских издержек компании. Последняя тенденция наблюдается в новых исследованиях, проведенных на развитых рынках. Также следует более подробно изучить влияние банковского мониторинга за счет расширения круга переменных.

Исследование приведенных выше факторов в динамике будет способствовать пониманию не только механизмов взаимодействия между регрессорами, но и позволит понять основные тенденции, присущие рынку российского корпоративного управления.

\section{Список литературы}

1. Долгопятова Т.Г. Собственность и корпоративный контроль в российских компаниях в условиях активизации интеграционных процессов // Российский журнал менеджмента. 2004. Т. 2. № 2. - С. 3-26.

2. Долгопятова Т.Г. Эмпирический анализ корпоративного контроля в российских компаниях: когда крупные акционеры отходят от исполнительного управления? // Российский журнал менеджмента. 2007. Т. 5. № 3. - С. 27-52.

3. Ковалев В.В., Либман А.В. Управление агентскими издержками в корпорации: Введение в проблему // Вестн. С.-Петерб. ун-та. Сер. Экономика. 2001. Вып. 4. C.47-60.

4. Швырков О. Инфраструктура корпоративного управления в России // Standard \& Poor's. 2008: <http://corp-gov.ru/upload/file/CG\%20in\%20Russia\%202008\%20$\% 20$ Rus $\% 20-\% 204$.pdf.

5. Яковлев А.А. Корпоративное управление и реструктуризация предприятий в России: формальные институты и неформальные интересы собственников // Экономический журнал ВШЭ. 2003. Т. 7. № 2. - С. 221-230.

6. Agrawal, A., and Knoeber, C.R. (1996), Firm performance and mechanisms to control agency problems between managers and shareholders, Journal of Financial and Quantitative Analysis. 31 (1996) 377-397.

7. Ang, J.S., Cole R.A., and Lin, J. Wuh (2000), Agency costs and ownership structure, Journal of Finance 55 (2000) 81-106.

8. Bhagat, S., and Black, B. (2002), The non-correlation between board independence and long-term firm performance, Journal of Corporations Law 27 (2002) 231-274.

9. Black, B., Jang, H., and Kim, W. (2006), Does corporate governance affect firms' market values? Evidence from Korea, Journal of Law, Economics and Organization 22 (2006), 366-413.

10. Brickley, J.A., Coles, J.L., and Jarrell, G. (1997), Leadership structure: separating the CEO and chairman of the board, Journal of Corporate Finance 3 (1997) 189-220.

11. Cremers, K.J.M, and Nair, V.B. (2005), Governance mechanisms and equity prices, Journal of Finance 60 (2005) 2859-2894.

12. Cai Charlie, X., Hillier, D., Tian Gaoliang, Qinghua Wu (2009), Agency Costs of Government Ownership: A Study of Voluntary Audit Committee Formation in China, working paper

13. Crutchley, C.E., Jensen, M.R.H., Jahera Jr, J.S., and Raymond, J.E. (1999), Agency problems and the simultaneity of financial decision making: The role of institutional ownership, International Review of Financial Analysis 8 (1999) 177-197. 
14. Demsetz, H., and Villalonga, B. (2001), Ownership structure and corporate performance, Journal of Corporate Finance 7 (2001) 209-233.

15. Eisenberg, T., Sundgren, S., and Wells, M. (1998), Larger board size and decreasing firm value in small firms, Journal of Financial Economics 48 (1998) 35-54

16. Henry, Darren (2006), Agency Costs, Corporate Governance and Ownership Structure: Evidence from Australia, working paper.

17. Fama, E. (1980), Agency problems and the theory of firm. Journal of Political Economy.

18. Fleming, G., Heaney, R., and McCosker, R. (2005), Agency costs and ownership structure in Australia, Pacific-Basin Finance Journal 13 (2005) 29-52.

19. Jensen, M.C. (1986), Agency costs of free cash flow, corporate finance and takeovers, American Economic Review 76 (1986) 323-339.

20. Jensen, M., and Meckling, W. (1976), Theory of the Firm: Managerial Behavior, Agency Costs, and Ownership Structure, Journal of Financial Economics 3 (1976) 305-360.

21. Jensen, G.R., Solberg, D.P., and Zorn, T.S. (1992), Simultaneous determination of insider ownership, debt and dividend policies, Journal of Financial and Quantitative Analysis 27 (1992)247-263.

22. McConnell, J.J., and Servaes, H. (1990), Additional evidence on equity ownership and corporate value, Journal of Financial Economics 27 (1990) 595-612.

23. Morck, R., Shleifer, A., and Vishny, R.W. (1988), Managerial ownership and market valuation, Journal of Financial Economics 20 (1998) 293-315.

24. Moh'd, M.A., Perry L.G., and Rimbey, J.N. (1995), An investigation of the dynamic relationship between agency theory and dividend policy, Financial Review 30 (1995) 367385.

25. Mak, Y.T., and Li, Y. (2001), Determinants of corporate ownership and board structure: evidence from Singapore, Journal of Corporate Finance 7 (2001) 235-256.

26. Shleifer, Andrei \& Vishny, Robert W. (1997), A Survey of Corporate Governance, Journal of Finance, American Finance Association, 52(2) (June 1997) 737-83,.

27. Singh, M., and Davidson, W.N. III (2003), Agency costs, ownership structure and corporate governance mechanisms, Journal of Banking and Finance 27 (2003) 793-816.

28. Weir, C., Laing, D.,.and McKnight, P.J. (2002), Internal and external governance mechanisms: Their impact on the performance of large UK public companies, Journal of Business Finance and Accounting 29 (2002) 579-611.

29. Yermack, D. (1995), Do corporations award CEO stock options effectively? Journal of Financial Economics 39 (1995) 237-269.

30. Yermack, D. (1996), Higher market valuation for firms with a small board of directors, Journal of Financial Economics 40 (1996) 185-211. 